\title{
Locating blockages in buried (telecoms) ducts: a new approach
}

Nicole Metje Dipl.-Ing., PhD, MCInstCES, MASCE

Department of Civil Engineering, School of Engineering, University of

Birmingham, Birmingham, UK (corresponding author:

n.metje@bham.ac.uk)

David Chapman BSc, PhD, MICE, CEng

Department of Civil Engineering, School of Engineering, University of

Birmingham, Birmingham, UK

Matt Stringfellow CGeol, MSci (Hons), FGS

Geophysics, RSK Environment Ltd, Hemel Hempstead, UK

Simina Rebegea PhD, MSC

Department of Civil Engineering, School of Engineering, University of Birmingham, Birmingham, UK

George Tuckwell PhD, FGS, CGeol, CSci

Geoscience and Engineering, RSK Environment Ltd, Hemel Hempstead, UK
Matt Guy MSc

Geomatrix Earth Science Ltd, Leighton Buzzard, UK

Neil Parkin MEng

BT Optical Network Research, Ipswich, UK

Daniel Roberts MRes, MSC

Department of Civil Engineering, School of Engineering, University of Birmingham, Birmingham, UK

Chris Leech BSC

Geomatrix Earth Science Ltd, Leighton Buzzard, UK

Andrew Lord BA

BT Optical Networks Research, Ipswich, UK

Buried infrastructure forms the backbone for economic stability, growth, competitiveness and productivity in modern society and is a critical element of urban environments. The pressures on buried infrastructure will only increase as the population increases, which will drive demand and require changes. This means that the maintenance of existing buried infrastructure, as well as building new capacity, is vital to meet demands. Currently, there is a lack of available technology to locate and detect accurately the condition of relatively shallow (up to $1 \mathrm{~m}$ deep) plastic ducts, supply pipes and drainage systems. As Fibre to the Premises (FTTP) is being rolled out across the UK, not accurately knowing the condition of the ducts (blocked, filled, damaged) can significantly increase the installation cost. To understand the real-world implications of the condition of the buried infrastructure, a buried duct test facility incorporating a range of different damage types was created. Both ground-penetrating radar and novel induct acoustics were shown to have the potential to be combined to detect different defects from partial to full blockage and multiple blockages in buried ducts, thereby allowing much better planning when installing FTTP.

\section{Introduction}

Despite the increasing ability to detect, characterise and monitor objects on land, in sea or in space, the ability to characterise buried objects, even in the near surface, has not significantly improved in the last 20 years. Even with the continuous development of newer multi-sensor equipment and more efficient data inversion and processing techniques, basic physical limitations and constraints remain, such as poor ground conditions and the trade-off between depth of penetration and resolution (Boddice et al., 2017). As the world engages in ever more complex and demanding transportation, utility networks and construction projects, incomplete knowledge of the subsurface is hampering modern-day business and societal activities and increasing national security risks. With an estimated $275000 \mathrm{~km}$ of gas pipes, $353000 \mathrm{~km}$ of sewers, $482000 \mathrm{~km}$ of electricity cables, $\sim 450000 \mathrm{~km}$ of water pipes and drains and several million kilometres of telecoms and street lighting in the UK, the problem is significant (Farrimond, 2008)

The majority of the UK's communication network is buried in ducts (conduits that house electricity or telecommunication cables), which are often several decades old. This has led to many of them becoming blocked due to collapsing ducts or in-fill from the surrounding substrate, which has rendered the spare capacity in the ducts unusable. The Office of Communications (Ofcom, 2017) analysed 79 build programmes and determined that there are between one and two blockages per kilometre but noted that this can vary significantly subject to the local situation such as geography. The costs of repair of these blockages are estimated to be between $£ 411$ and $£ 648$ per blockage (Openreach, 2020). There is currently no surface detection technology that can accurately locate the position of these defects (or, in some cases, even accurately locate the ducts at all). Remote detection of buried assets is done using geophysical sensors; however, identifying damage or blockages in ducts, which limit their capacity, is an enormous challenge. Traditionally, identifying damage or blockages is mainly done manually using rodding, where flexible rods are pushed through the duct to identify the location of the blockage. This poses several difficulties: $(a)$ the rodding length is limited, $(b)$ it requires access to the inside of the duct through an inspection chamber and (c) it identifies only the first blockage and not the subsequent ones. This can negatively impact on the workflow, as repairs are often done on an ad hoc basis, repairing one blockage at the time. This results in inefficient repair planning, increasing the costs and causing disruption to road users. It is estimated that the annual cost of clearing blockages in ducts in the UK is several million pounds, but the costs from the disruption to the workflow and additional time from delays are significantly greater. It is important to differentiate between direct repair and indirect repair costs, which add to the total cost of a repair. The indirect cost can include, among other things, repeated mobilisation of the repair team as new blockages are discovered, delays to installation of new fibres 
and additional fencing off a site with potential traffic management while waiting for the repair to occur. Thus, the saving in repair costs are not related to the direct costs, but the indirect costs that can be significantly reduced if blockages are identified in one process to enable the installation of Fibre to the Premises (FTTP). If this is widened out to waste water drainage and highway drainage systems, where similar defects and blockages can occur, then the potential impact of finding a robust solution to the problem of detection will be enormous. The drive to proactive asset management has been recognised in other areas such as earthwork management where Burland et al. (2012) stated that a reliable system of appraisal, maintenance and repair is needed to keep the asset in good condition. While the focus of the paper is on telecom ducts, it should be noted that the issue of blockage is not limited to ducts but also occurs in drainage and pressurised water pipes, often as a result of corrosion or tree root ingress (e.g. Kim et al., 2017; Papadopoulou et al., 2008; Torres et al., 2017).

This paper initially reviews different geophysical sensing technologies used not only to mainly locate the position of buried assets but also to assess the condition from the ground surface, and those used to assess the condition from inside ducts. A shortlisted subset, as well as a new technique, is then evaluated further to assess their potential to detect blockages in buried ducts. This is facilitated by the construction of a new test site enabling controlled tests to be conducted on ducts buried at different depths and incorporating different defects. Novel postprocessing techniques were developed to generate a level of detailed information that would make a step change to standard practice in mapping and assessing the condition of buried infrastructure. The contribution of the paper to knowledge is the novel use of existing geophysical technologies, development of a prototype of a new sensor and the associated processing to retrieve the maximum of information from the collected data with respect to duct defects.

\section{Shortlisting of appropriate sensing technologies}

To identify the most appropriate geophysical sensing technology, a range of technologies were assessed against the following criteria based on the industrial need:

to detect the location and depth of 50 and $100 \mathrm{~mm}$ dia. service ducts (generally plastic ducts) using remote sensing systems

- to detect the location of blockages or damage within the service ducts.

A variety of techniques were considered, including acoustic detection, ground-penetrating radar (GPR), electromagnetic location (EML) and closed-circuit television (CCTV). More information on the theoretical background of operation of these techniques can be found in, for example, the publications by Utsi (2017), Reynolds (2011), Jol (2009), Butler (2005), McDowell et al. (2002), Das et al. (1990) and Milsom and Eriksen (2011). GPR is a proven technique for detecting metallic and non-metallic buried objects including plastic pipes or ducts and voids (Demirci et al., 2012; Hunaidi and Giamou, 1998; Pettinelli et al., 2009; Plati and Derobert, 2015). GPR systems transmit (Tx) an electromagnetic (EM) radio wave into the ground and record the amplitude and time for the reflected energy to return to the receiver $(\mathrm{Rx})$, often situated parallel to the ground (also known as ground coupling) (Annan, 2009). The frequency bandwidth selected for utility detection is typically between $100 \mathrm{MHz}$ and $1 \mathrm{GHz}$ (Thomas et al., 2006). Assuming a wave velocity of $0.08 \mathrm{~m} / \mathrm{ns}$ (based on a dielectric value of 14 , typical for damp sand (Cassidy, 2009)), the wavelength of a $250 \mathrm{MHz}$ and $1 \mathrm{GHz}$ wave will be 0.32 and $0.08 \mathrm{~m}$, respectively (Koppenjan, 2008). The minimum resolvable target size is typically one-fourth of the wavelength, which means that the smallest resolvable targets at these frequencies are 0.08 and $0.02 \mathrm{~m}$, respectively (Jol, 1995; Perez-Gracia et al., 2009; Rial et al., 2009). If the ground conditions change and the water content increases, the wave velocity will reduce, increasing the resolution; thus, smaller targets can be resolved. However, this may inhibit the EM wave propagation and limit the depth of penetration required for the targets of interest (Weiler et al., 1998). The most common diameter for communication cable ducts are 50 and $90 \mathrm{~mm}$ and are typically installed at a minimum depth of $0.25-0.60 \mathrm{~m}$ (Openreach, 2019) under pavements and road carriageways, respectively. The maximum depth of exploration is governed by the dynamic range of the GPR system and the ground conditions (most importantly the ground conductivity and antenna coupling).

Ground surface variations and heterogeneous subsurface material add undesirable and uncontrollable inconsistencies, which will limit the reliability of detecting blockages within buried ducts using surface geophysics. Vibro-acoustic methods have demonstrated the ability to track utility pipelines over tens of metres (Muggleton and Brennan, 2012; Muggleton et al., 2011). One such method relies on propagating a compressional or shear wave through the ducting or pipe material and then recording the acoustic wave at the ground surface. In this case, the acoustic source is in direct contact with the duct or pipe. The technique has been thoroughly evaluated as part of the Mapping the Underworld project (MTU, 2021), but to date, no commercial systems dedicated to this particular application are available. In-pipe technologies were also evaluated for detecting blockages within ducts. Many commercial systems are available for identifying blockages and leaks within pipes used for industrial manufacturing. In most cases, a pressure wave is propagated down the pipe. The reflected and/or diffracted energy is measured by a set of receivers located coincidentally with the transmitter. The amplitude, frequency and travel time are analysed to determine the location of the blockage/leak and the cross-sectional area of the pipe.

Acoustic reflectometry (AR) has recently been adopted for locating blockages within sewer pipes (Long and Faram, 2014). The method transmits an acoustic wave typically between $100 \mathrm{~Hz}$ and $15 \mathrm{kHz}$ by way of a standard audio transmitter and records the amplitude and travel time of the reflected energy to return to the origin of the source (Ali, 2010). The transmitter and receiver geometry are small, $75 \mathrm{~mm}$ dia. and $200 \mathrm{~mm}$ long, allowing the system to be deployed at the head of a duct located within an 
Table 1. Geophysical techniques with advantages and limitations that were considered for the detection of defects in buried ducts (adapted from Datta and Sarkar (2016))

\begin{tabular}{|c|c|c|c|}
\hline Technique & Deployment & Advantages & Limitations \\
\hline Microgravity/gravity gradient & $\begin{array}{l}\text { Ground } \\
\text { surface }\end{array}$ & $\begin{array}{l}\text { Potential to discriminate between a } \\
\text { clear and blocked piped by plotting } \\
\text { small density variations }\end{array}$ & $\begin{array}{l}\text { Above-ground structures influence microgravity } \\
\text { measurements. Applying corrections to isolate } \\
\text { subsurface anomalies from above-ground anomalies } \\
\text { requires vigorous quality control measures, which } \\
\text { are time consuming. } \\
\text { Productivity is comparatively slow compared with } \\
\text { that of other geophysical methods. } \\
\text { Unlikely to resolve blockages in ducts due to the } \\
\text { small diameter and small density contrast. } \\
\text { The anomaly breadth at the ground surface from a } \\
\text { small discreet volume of sediment in a } 100 \text { or } \\
50 \text { mm duct will be significantly larger than the size } \\
\text { of the blockage. }\end{array}$ \\
\hline Seismic reflection & $\begin{array}{l}\text { Ground } \\
\text { surface }\end{array}$ & Well understood within the industry & $\begin{array}{l}\text { Susceptible to random noise from passing traffic } \\
\text { (foot and vehicle traffic). } \\
\text { An array of geophone receivers would need to be } \\
\text { deployed above the duct. } \\
\text { Achieving adequate contact between the } \\
\text { geophones and ground surface for resolving high } \\
\text { frequency compressional waves is unlikely. } \\
\text { An accurate topography map is required to perform } \\
\text { static corrections. } \\
\text { Productivity is comparatively slow compared with } \\
\text { that of other geophysical methods. } \\
\text { A skilled operator is required to quality control data } \\
\text { acquisition. }\end{array}$ \\
\hline $\begin{array}{l}\text { Direct current electrical ground } \\
\text { resistivity }\end{array}$ & $\begin{array}{l}\text { Ground } \\
\text { surface }\end{array}$ & $\begin{array}{l}\text { Simple easy-to-use equipment } \\
\text { Theory well understood }\end{array}$ & $\begin{array}{l}\text { Requires the duct, or content of the duct, to } \\
\text { support a current. } \\
\text { Tarmac, concrete, block paving, gravel surface } \\
\text { material is highly resistive and would require special } \\
\text { electrical contacts. } \\
\text { Productivity is comparatively slow compared with } \\
\text { that of other geophysical methods. }\end{array}$ \\
\hline $\begin{array}{l}\text { Electromagnetic ground } \\
\text { conductivity mapping }\end{array}$ & $\begin{array}{l}\text { Ground } \\
\text { surface }\end{array}$ & $\begin{array}{l}\text { Rapid data acquisition } \\
\text { Simple to operate }\end{array}$ & $\begin{array}{l}\text { Sensitive to above-ground conductive objects as } \\
\text { well as subsurface features. } \\
\text { Depth is poorly resolved. }\end{array}$ \\
\hline $\begin{array}{l}\text { Pulse echo analysis (Duan et al., } \\
\text { 2015) }\end{array}$ & $\begin{array}{l}\text { Through } \\
\text { ducts }\end{array}$ & $\begin{array}{l}\text { Will determine the length to and } \\
\text { cross-sectional area of a blockage }\end{array}$ & $\begin{array}{l}\text { Less sophisticated than AR but very similar in } \\
\text { principle. } \\
\text { Not reliable for detecting short blockages. }\end{array}$ \\
\hline $\begin{array}{l}\text { Transient wave blockage } \\
\text { interaction and blockage } \\
\text { detection (Duan et al., 2014) }\end{array}$ & $\begin{array}{l}\text { Through } \\
\text { ducts }\end{array}$ & Precise & $\begin{array}{l}\text { Only proven when fluid is flowing through a pipe, } \\
\text { likely to be difficult to couple to air. } \\
\text { Method realised on repeatable wave amplitude at } \\
\text { even harmonics. } \\
\text { More suited to permanent installation for } \\
\text { monitoring sediments in short sections of industrial } \\
\text { pipelines. }\end{array}$ \\
\hline $\begin{array}{l}\text { Impedance method (Kim, } \\
\text { 2014) }\end{array}$ & $\begin{array}{l}\text { Through } \\
\text { ducts }\end{array}$ & $\begin{array}{l}\text { Proven to locate blockages and leaks } \\
\text { in pipes }\end{array}$ & $\begin{array}{l}\text { Only proven when fluid is flowing through a pipe, } \\
\text { likely to be difficult to couple to air. } \\
\text { Mathematical computation is complex. }\end{array}$ \\
\hline $\begin{array}{l}\text { Radioisotope technology } \\
\text { (Robins, 2005) }\end{array}$ & $\begin{array}{l}\text { Through } \\
\text { ducts }\end{array}$ & $\begin{array}{l}\text { Can numerate the quantity of } \\
\text { deposition in a pipe }\end{array}$ & $\begin{array}{l}\text { Requires an active gamma source. A licence is } \\
\text { required to handle radioactive sources. } \\
\text { Access to the outer face of the pipe/ducts is } \\
\text { required. } \\
\text { Gamma count will be determined by the type of } \\
\text { alluvia sediment washed into the duct. }\end{array}$ \\
\hline
\end{tabular}

inspection chamber. The amplitude of the reflected energy relates to the size of the blockage, while the polarity indicates if the cross-sectional area of the duct has increased or decreased. A high amplitude reflection with reverse polarity generally indicates an open-ended pipe (Wang et al., 2009) with no or minimal blockage defects. If a duct is completely blocked, all the transmitted energy may be reflected back to the source origin and any subsequent blockages along the duct will not be identified. In this case, 
acoustic transillumination (AT) may provide a solution. This technique requires access to both ends of the duct. An acoustic transmitter is placed at one end and a receiver at the other. The direct travel time and amplitude of the received signals are recorded and analysed. No commercial systems dedicated to this particular application are currently available. However, the dynamic range and bandwidth of most exploration seismographs are suitable for the application.

It was anticipated that the results from in-pipe acoustic technology would help constrain the surface obtained GPR data sets during processing and help provide a faster analysis and improved interpretation of the data. Table 1 summarises the different techniques considered during the research together with the advantages and limitations.

To evaluate those techniques that had the most potential, a training facility owned by BT for their in-house operator training was used, as this contained existing known and unknown buried infrastructure, although there was no information on duct condition or information about any blockages. The area was approximately $30 \mathrm{~m}$ by $30 \mathrm{~m}$ in size and contained single, twin and quad configurations of buried ducts at various depths up to $2 \mathrm{~m}$. The site was surveyed at the start of the project by deploying a full PAS 128 (BSI, 2014) survey on it, together with full cover lifting and CCTV surveys of the ducts. A variety of GPR systems (single channel, dual channel, tri-channel and multiple array) and antenna frequencies from $200 \mathrm{MHz}$ up to $1.5 \mathrm{GHz}$ were utilised to evaluate the most efficient survey strategy. Frequency-domain electromagnetics and high-resolution three-dimensional (3D) seismics were also tested. Acoustic methods using both reflectometry and transillumination were investigated using an offthe-shelf $30 \mathrm{~W}$ audio speaker for the source combined with a unidirectional microelectromechanical systems microphone with a $65 \mathrm{~dB}$ signal-to-noise ratio. The analog to digital digitiser had a dynamic range of $128 \mathrm{~dB}$ and a bandwidth of $2 \mathrm{~Hz}-8 \mathrm{kHz}$. A variety of sweeps were trialled, and a $400 \mathrm{~ms}$ linear sweep from 35 to $500 \mathrm{~Hz}$ proved most successful in resolving blockages of greater than $1 \mathrm{~cm}$ at distances over $200 \mathrm{~m}$, although it should be noted that the resolution reduces with distance due to high frequencies being attenuated. Table 2 summarises the sensors used.

Six inspections were carried out on selected buried ducts using a colour CCTV inspection camera. The inspections were limited to ducts with sufficient space for the CCTV camera to fit through. A variety of conditions were recorded, including $(a)$ steep bend in a duct, (b) partially water-filled ducts and (c) blocked/damaged ducts due to collapse (see Figure 1 for example CCTV images from within ducts showing a partial blockage and a partially water-filled duct). Three AR tests were carried out using a sweep of sound (low to high frequency) transmitted inside the duct (see Figure 2). The travel time of the reflected wave indicated the locations of any defects. This was also a simple and reliable means of determining the duct length to within $\pm 0.25 \mathrm{~m}$ (using AT, this can be reduced to $\pm 0.15 \mathrm{~m}$ ).
Figure 3(a) shows the results from the AR for a duct in a good condition. This clearly shows the duct joints and the end of the duct. The results were confirmed by the CCTV investigation. In contrast, Figure 3(b) shows the results for a second duct, which indicated a range of blockages between the start and the end of the duct at $27 \mathrm{~m}$. The first (partial) blockage was shown at a distance of $13.44 \mathrm{~m}$, which was confirmed by CCTV with an additional peak suggesting a second, unconfirmed blockage at approximately $19.00 \mathrm{~m}$. Duct joints can be detected by AR only if the wave propagates towards the socketed end of the duct - that is $\mathrm{AR}$ can detect joints only in one direction. However, if a combination of AR and AT is used, then duct joints can be identified without the need to collect measurements from both ends of the duct.

The GPR survey utilising a single-channel antenna was carried out at a line spacing of $0.5 \mathrm{~m}$ in both orientations. Multiple frequencies, arrays and different manufacturer's equipment were used (see Table 2). The results were also compared with initial modelling results using ReflexW. Figure 4 shows some selective results.

Figure 4(b) shows that double ducts cannot be resolved, as they are too close to adjacent ducts (within $200 \mathrm{~mm}$ ). Multiple ducts on top of each other are represented as additional ringing in the data. Blocked or silted ducts (see Figure 4(d)) were easily detectable. Overall, GPR antennas with a frequency range between 400 and $900 \mathrm{MHz}$ proved most appropriate for this application with good resolution and good depth penetration for ducts of this size and depth typical of BT assets. Frequencies over $1 \mathrm{GHz}$ resulted in a better resolution but did not provide enough depth penetration for typical BT ducts (i.e. below $350 \mathrm{~mm}$ ).

While the EML technique is useful for duct location in the first instance, it does not provide any information on duct condition unless a tracer cable or sonde is fully inserted, which does not provide any further advantage over rodding. CCTV cameras

\section{Table 2. Equipment used during the initial field trials}

\begin{tabular}{|ll|}
\hline Method & \multicolumn{1}{c|}{ Instrument/technology } \\
\hline EML & Radiodetection RD8000 \\
Acoustics & Reflectometry \\
& Transillumination \\
GSSI $400 \mathrm{MHz}$ single channel \\
GSR & GSI 300 and $800 \mathrm{MHz}$ dual frequency \\
& GSSI $1500 \mathrm{MHz}$ single channel \\
& IDS Stream C array (600 MHz 32 channel) \\
& Utsi Electronics $4 \times 4000 \mathrm{MHz}$ array \\
& Utsi Electronics TriVue (250, 500 and $1000 \mathrm{MHz})$ \\
\hline Electromagnetics & Geonics EM38MK2 \\
Seismic & Three-dimensional array with Geometrics Geode \\
& (14 Hz P and S wave phones) and vibrator \\
Direct & Source \\
observation & Cover lifting \\
& Manhole chamber inspection and detailing \\
& CCTV survey of accessible ducts
\end{tabular}




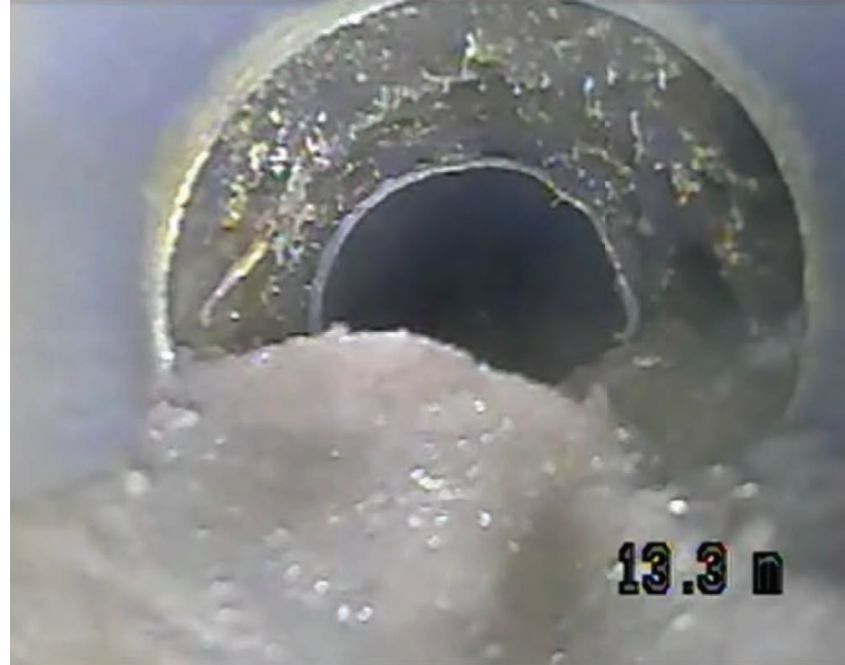

(a)

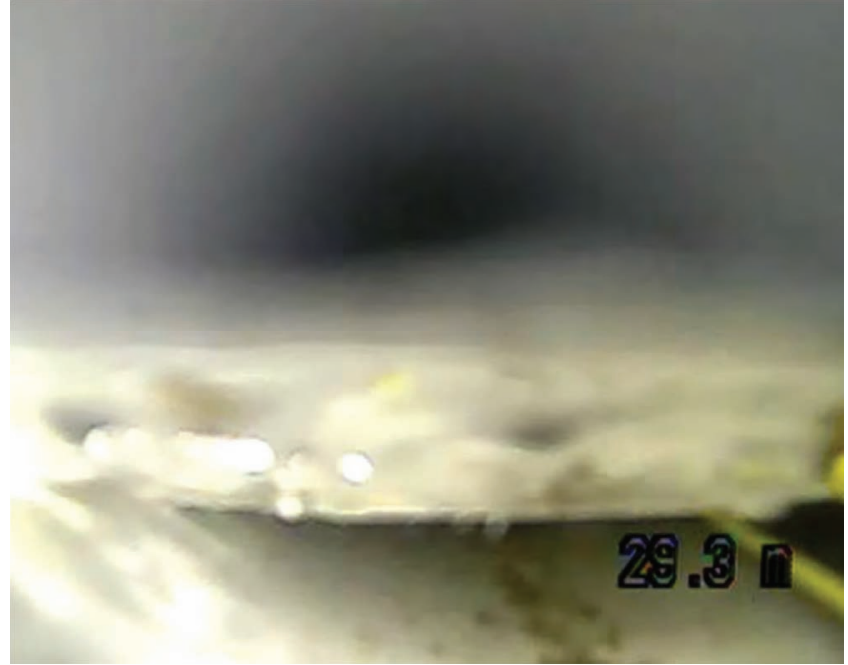

(b)

Figure 1. CCTV images from within ducts showing (a) a partial blockage and (b) a partially water-filled duct

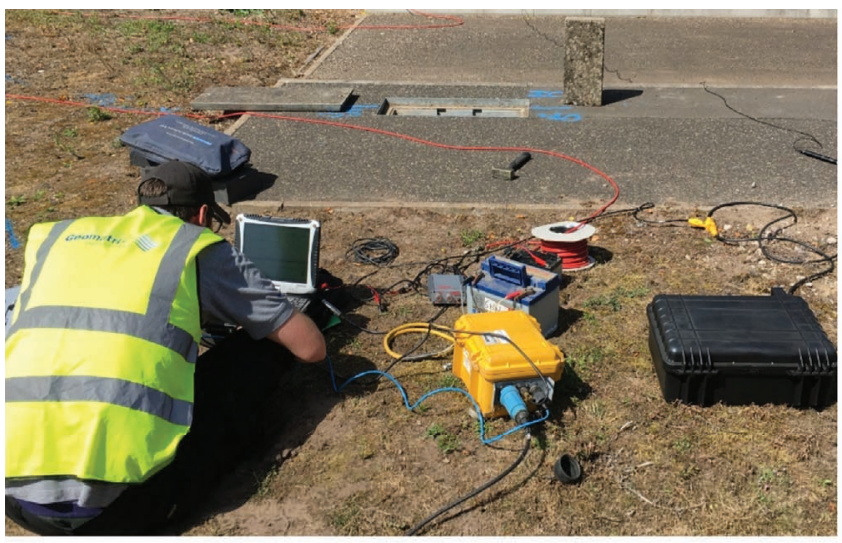

(a)

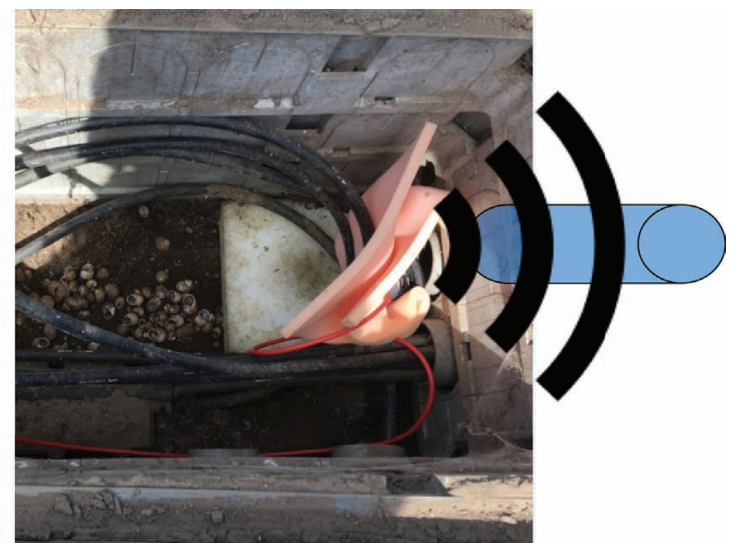

(b)

Figure 2. AR in use in the field: (a) operator with a laptop; (b) the microphone located at the end of the duct in a manhole, with annotation diagrammatically showing the duct and black lines representing the direction of the acoustic wave

suffer from the same issues as rodding in that they can detect only the first blockage, although the detail of what is causing the blockage would be clearer. However, the additional cost of CCTV would not be cost effective in most circumstances for the current application. The EM and seismic techniques were shown so as not to provide the required resolution to detect blockages in ducts. However, EM may still be beneficial in indicating areas of unforeseen ground conditions, such as saturated ground from water pipe leakage.

Based on the preliminary investigations, it was concluded that GPR as an over-the-ground technique, together with AR and AT for induct inspection, showed the greatest promise in relation to detecting the duct and any defect along its length. After shortlisting these two techniques, it was important to evaluate further their capability to detect a range of different defects combined with different processing methods under more controlled conditions. Thus, a bespoke test site was constructed, which is described in more details in the following section.

\section{Test facility}

To provide a controlled test site with known features at a known depth and with variable defects, a bespoke test site was constructed. Following the preliminary GPR surveys on the BT training facility grounds, a clear area (i.e. no known buried assets) of ground $15 \times$ $10 \mathrm{~m}$ in size was selected to install ducts with known defects under controlled conditions. The ground at the test site comprised sandy soils with glacial sand and gravel, of approximately $6 \mathrm{~m}$ thickness 
over Red Crag Sand (BGS (2018) borehole immediately south of the site), suggesting excellent drainage, which implies that precipitation has little impact on the soil water content. A particle size distribution analysis of the soil in the area of the bespoke test facility was conducted according to BSI (1990) and described as an orangey brown silty sand. As the permittivity is important, time-domain reflectometry probes as used by Curioni et al. (2017) were installed close to the bespoke facility to provide an indication of the local permittivity at two locations and at three vertical depths $(0.10,0.35$ and $0.60 \mathrm{~m}$ ). The permittivity ranged between 5 and 11 in November 2017 and between 10 and 16 in January 2018, indicating a higher water content in 2018. The permittivity impacts in particular the

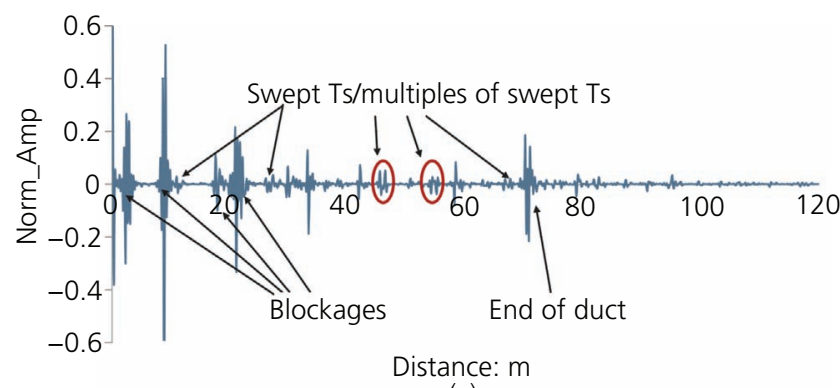

(a)

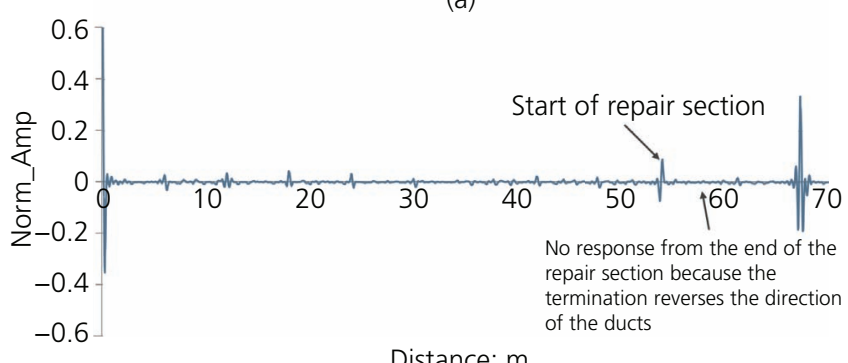

(b)

Figure 3. Results from the AR investigation for (a) blind test and (b) a repair wave velocity of the GPR (see Utsi, 2017), but the impact is minimal within the two ranges due to the sandy soil. A change in permittivity of 4 would lead to $\approx 0.04 \mathrm{~m} / \mathrm{ns}$ and therefore an error of $0.012 \mathrm{~m}$ in depth, $10 \%$ of the duct diameter.

A total of five ducts, each approximately $10 \mathrm{~m}$ long, were installed at depths ranging from approximately $0.2-0.8 \mathrm{~m}$ below the ground surface with a range of defects (Figure 5 shows the site layout) with new inspection chambers (i.e. manholes) at either end to allow access to the ducts. The ducts were buried within the depth range of typical telecom ducts $(0.2-0.5 \mathrm{~m})$ and drainage/ water pipes, which were buried nominally between 0.8 and $1.2 \mathrm{~m}$ (NJUG, 2018), although in practice there could be significant divergence from these depths and offsets. Due to practical limitations, the maximum depth achieved on the site was $0.8 \mathrm{~m}$. The defects were chosen to simulate typical defects, including offsets (duct C); differently sized holes simulating breakage in the top of the duct (duct B); empty ducts to allow the simulation of partial blockages (duct A); changes in depth, which is common (duct D); and a change in material, including a corroded metal pipe to simulate a water pipe (duct E). The ducts were spaced $2.5 \mathrm{~m}$ apart to ensure that there was no overlap in the GPR reflections when surveyed perpendicular to the ducts. Each duct run was approximately $10 \mathrm{~m}$ long. This resulted in a test area approximately $13 \mathrm{~m}$ wide by $11 \mathrm{~m}$ from which a 3D GPR data cube was acquired and interrogated for the analysis of the ducts, the defects and the surrounding ground. Duct A was used for the majority of the variable blockage tests, as the other ducts already had various fixed defects. The blockages ranged from 10 to $60 \%$ annular blockage, a range of materials (to simulate tree root blockage) and variable separation of the blockage to test the resolution. Each blockage was approximately $300 \mathrm{~mm}$ long. Partial blockage of the ducts was achieved by pulling a range of different objects of different sizes through the ducts (see Figure 6). This included tree branches and plastic cylinders filled with sand, air and twigs to simulate different densities of blockages. Tests were set up by pulling the blockage through the

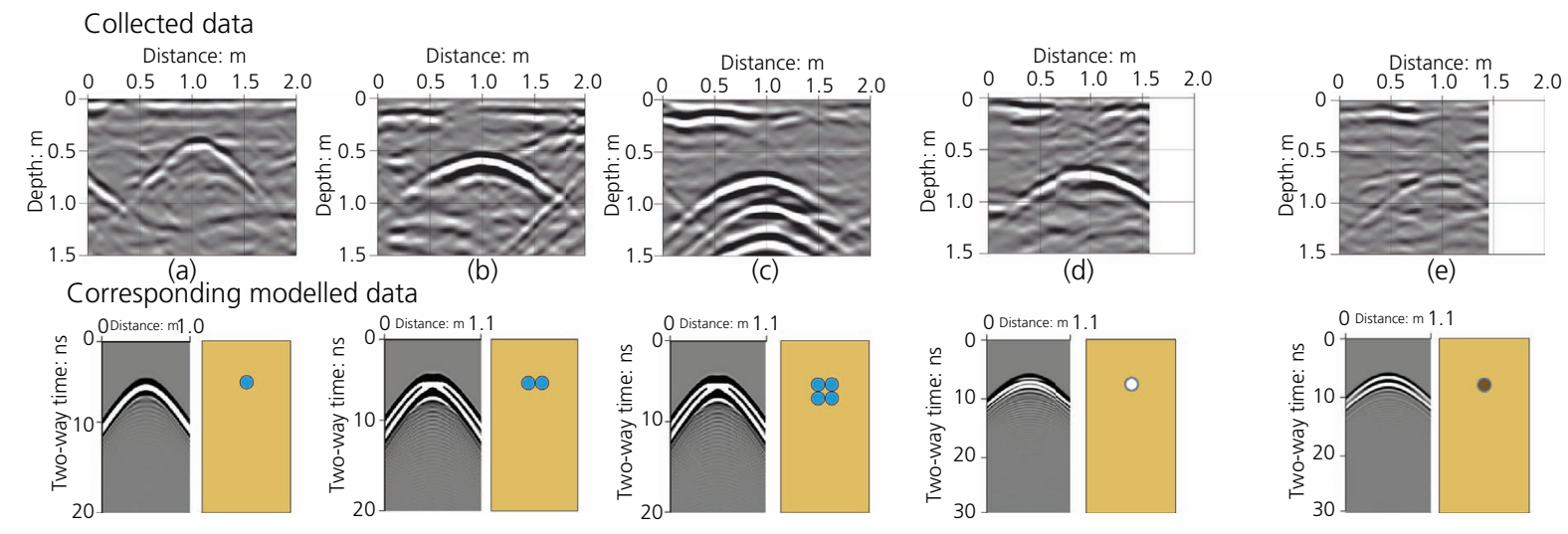

Figure 4. Two-dimensional radargrams for (a) single, (b) double and (c) multiple ducts, showing a comparison between measured and modelled results, and (d) single empty duct and (e) single silted duct 
Smart Infrastructure and Construction Volume 175 Issue 2
Locating blockages in buried (telecoms)

ducts: a new approach

Metje, Chapman, Stringfellow et al.

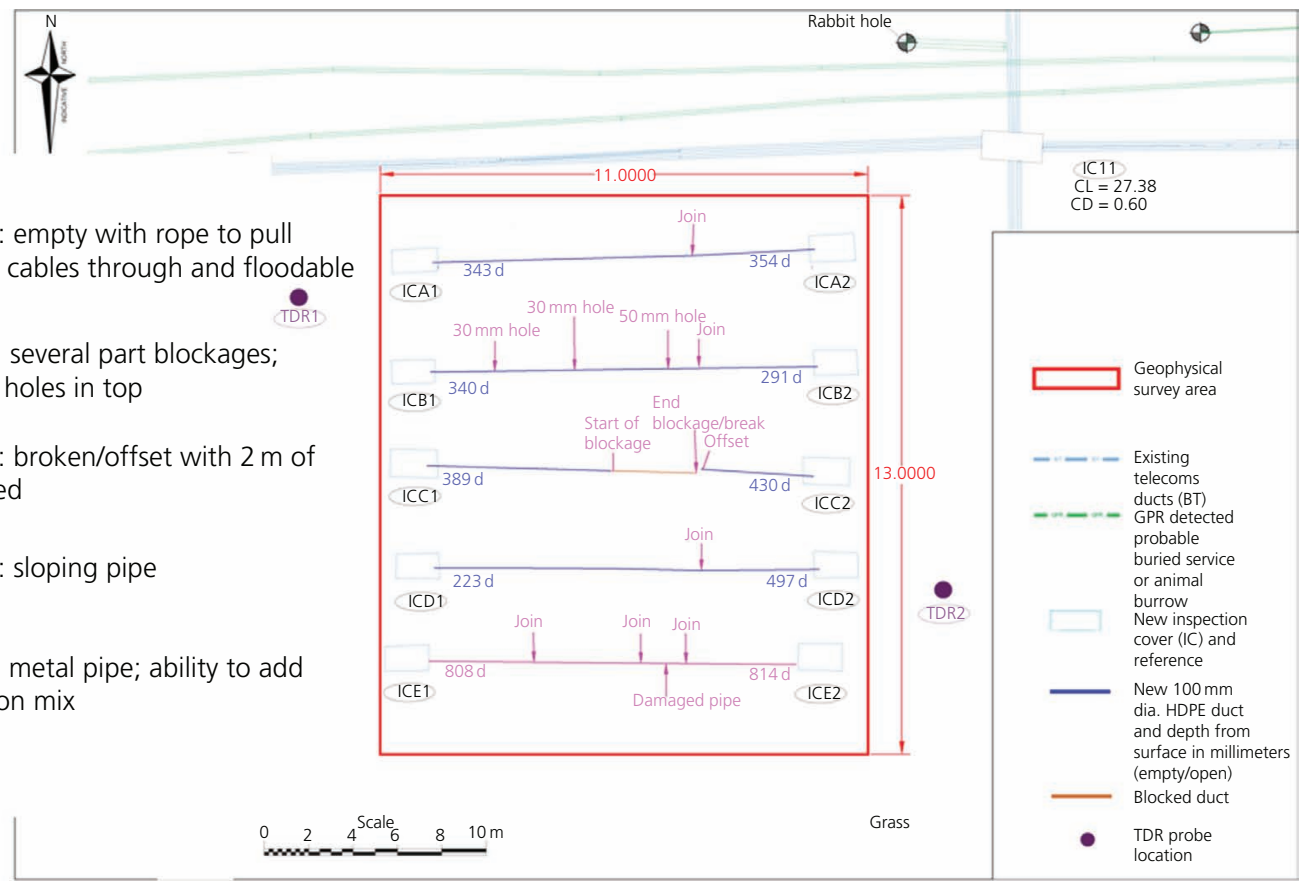

Figure 5. Site layout showing ducts A to E together with their depth below ground surface and defects. HDPE, high-density polyethylene
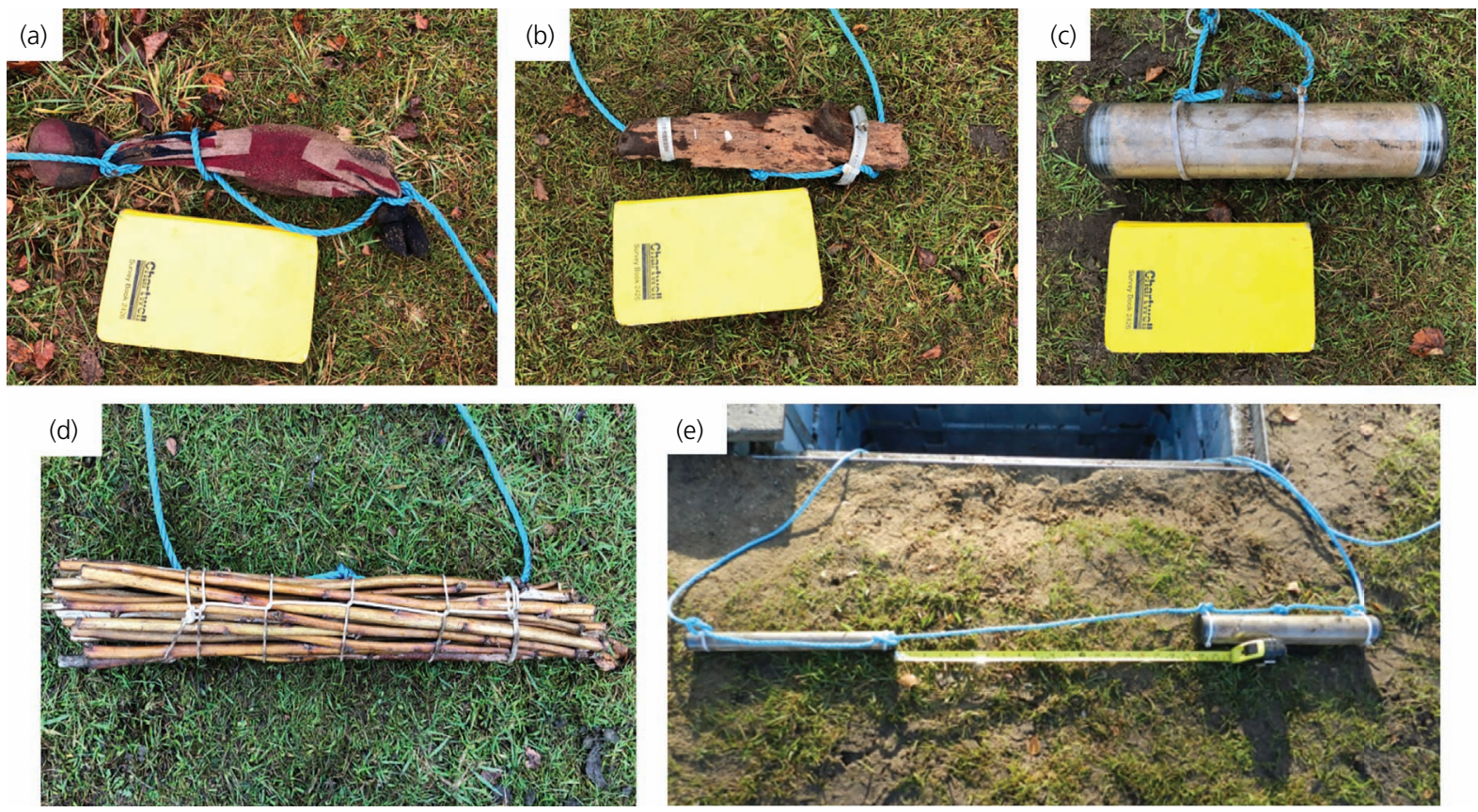

Figure 6. Different blockages (a) filled material bag, (b) driftwood simulating a large root, (c) container filled with soil, (d) wooden staves as a proxy for small roots and (e) multiple blockages separated by a known distance. The survey book is added for scale

duct on a rope to a set distance, and then both AR and GPR surveys were conducted. Moreover, tests were conducted to evaluate if the capacity within a duct (important to assess if there is space for new fibre optics to be placed in the duct) could be detected by testing the ducts empty, through two to nine cables to simulate capacity from 0 to $100 \%$. Finally, ducts were also filled with water to simulate flooding to observe the effects on the GPR data. A total of 69 AR and 29 GPR trials were carried out. 


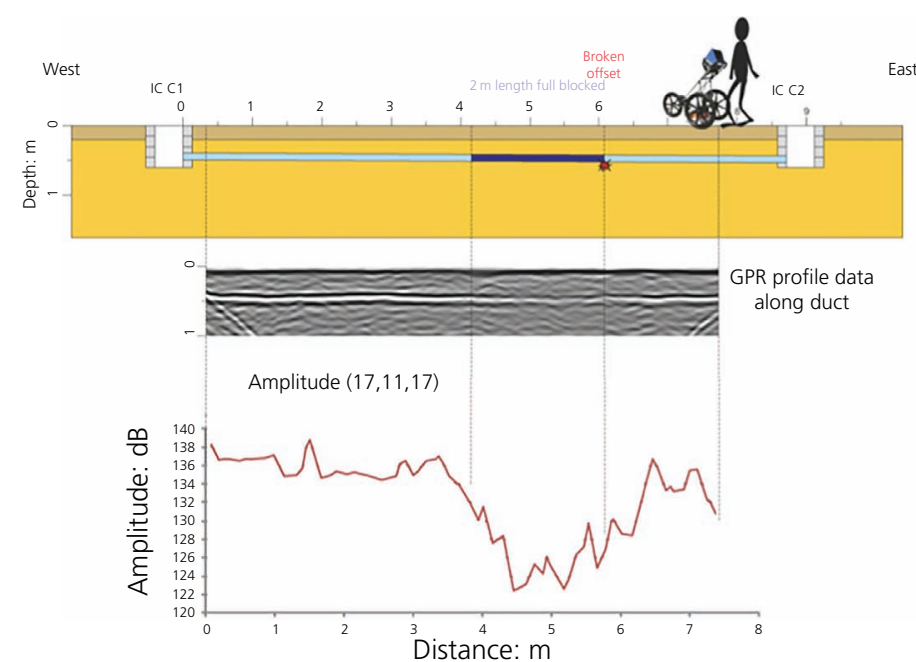

(a)

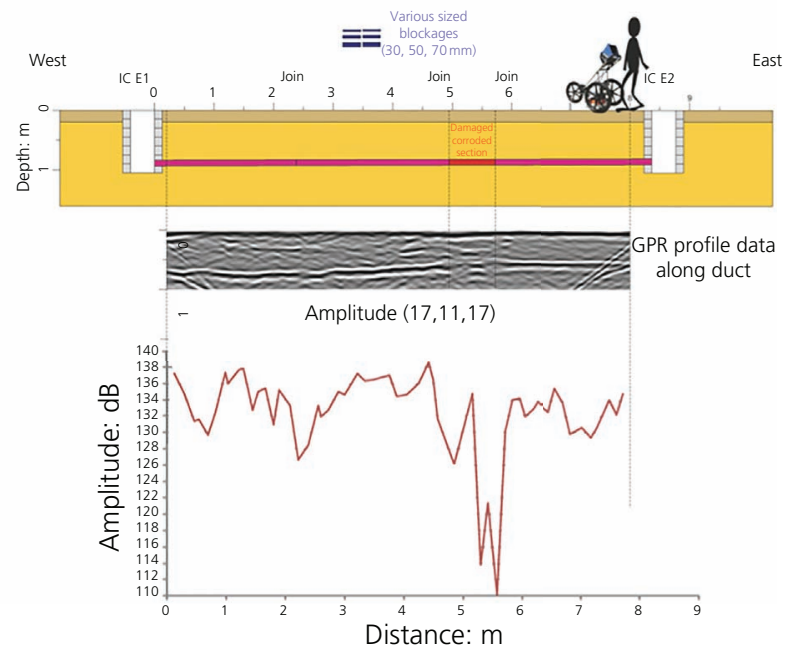

(b)

Figure 7. Example of the GPR results for (a) duct $C$ and (b) duct $E$ together with the amplitude plot

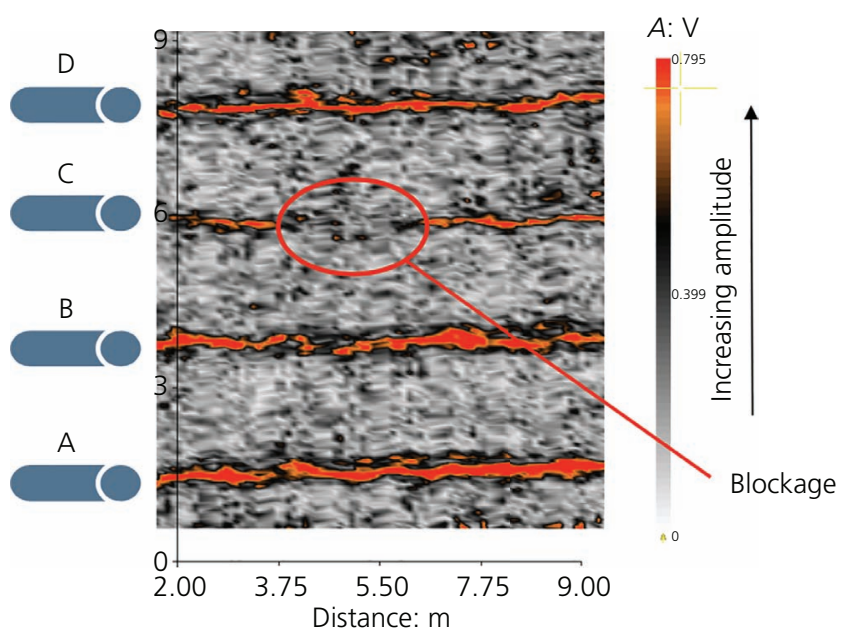

Figure 8. Amplitude power plot for ducts A to D (plastic pipes) the reduction in amplitude indicates a blockage in duct $C$ (plan view)

\section{Results}

GPR surveys were conducted using GSSI single-channel $400 \mathrm{MHz}$, IDS 32-channel $600 \mathrm{MHz}$ and Utsi Electronics $1 \mathrm{GHz}$ (four receivers with single transmitter to calculate velocity) GPR systems. AR and AT were conducted using a Geometrics Geode seismograph and off-theshelf acoustic amplifier, speaker and microphone during two different visits to the test site. Selected GPR results from ducts $\mathrm{C}$ and $\mathrm{E}$ are shown in Figure 7. In duct $\mathrm{C}$, there is a $2 \mathrm{~m}$ length of blocked duct, which in the GPR radargram profile data can only be identified by marginally blurring the image, but is much more clearly evident in the amplitude values (indicated by a significant, 32\%, drop in amplitude in the region of the blockage). In duct $\mathrm{E}$, there is a damaged/corroded section of pipe, which can be seen both in the GPR radargram profile as a blurring of the image and also by a significant drop in amplitude of the signal in this location. Figure 8 shows a plan view of the GPR amplitude power plot acquired along the axis of ducts $\mathrm{A}$ to $\mathrm{D}$, which again indicates a noticeable difference in the amplitude response where there is a blockage in duct $\mathrm{C}$ (i.e. duct filled with soil). The difference is attributable to the absence of the voided duct, as the dielectric contrast between a voided duct and soil is higher than that between a filled-in duct and soil. Figures 9(b) and 9(c) show the results for a 'soil blockage' (plastic tubes of different sizes were filled with soil and positioned in the duct) for 10 and $60 \%$ blockages with the associated $400 \mathrm{MHz}$ radargram profiles collected perpendicular to the duct. At first sight, there was a slight variation to the radargram obtained for the empty duct (Figure 9(a)), and when investigating the amplitude, it also showed a small drop between 5 and $14 \%$, but this was similar to the noise in the data. Similar results were found for tree roots (Figures 9 (d) and 9(e)), indicating that the GPR was not able to detect these blockages clearly.

AT signals corresponding to duct A with and without blockages are shown in Figure 10. Figure 10(a) clearly shows the reflection from the duct end and indicates that the duct is intact, as there is a flat response between the duct end and the first multiple. The record also contains multiples from the duct end because the acoustic energy is trapped within the duct. Multiples can easily be identified because their travel time is a multiple of the origin. As part of the Finding Infrastructure with Non-destructive Imaging Technologies (FINDIT) project, a simple program was created to identify multiples. In contrast, Figure 10(b) indicates the existence of a blockage between the duct end and the first multiple noticeable by the fact that the response is no longer flat. The focus moved to AT rather than reflection because the measurement proved more suitable for developing additional analysis tools required to distinguish in-duct features (defects, joints and Swept-Ts) from their respective multiples. Because the AT measurements result from the direct travel (i.e. source to receiver) as well as reflected travel yields additional analytics. Comparing the theoretical attenuation of multiples from the 


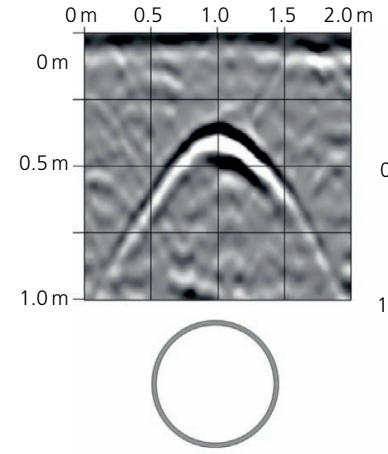

(a)

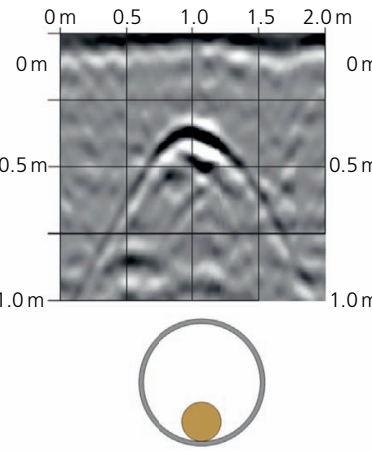

(b)

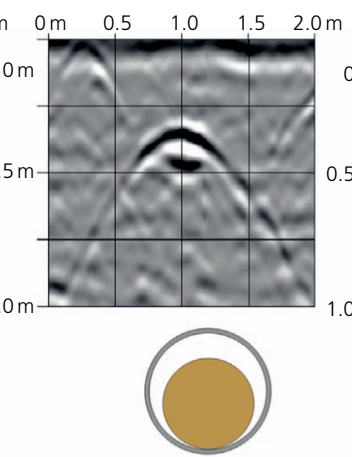

(c)

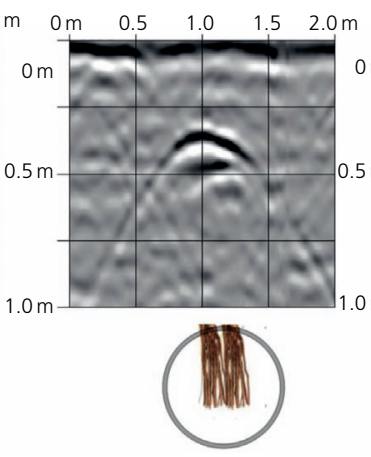

(d)

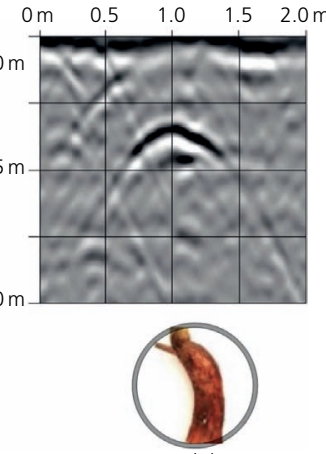

(e)

Figure 9. Radargrams for the $400 \mathrm{MHz}$ GPR taken perpendicular to the duct for (a) an empty duct, (b) $10 \%$ blockage, (c) $60 \%$ blockage, (d) small roots and (e) large root

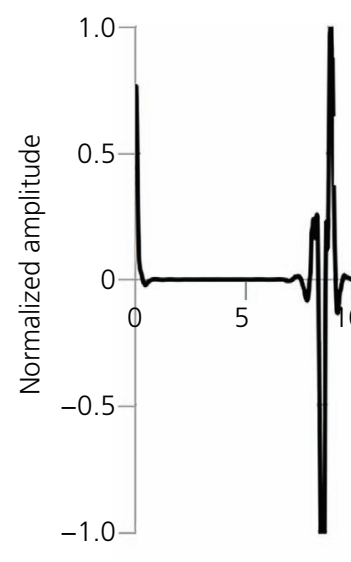

Duct end response

indicates duct is intact

Flat response between duct end and first

multiple indicates no blockages

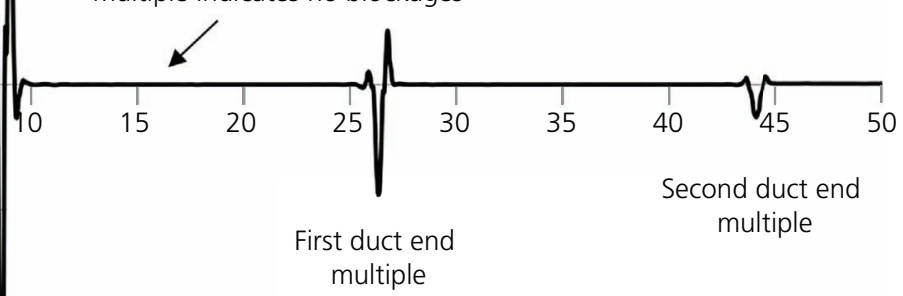

Duct end

Distance: $m$

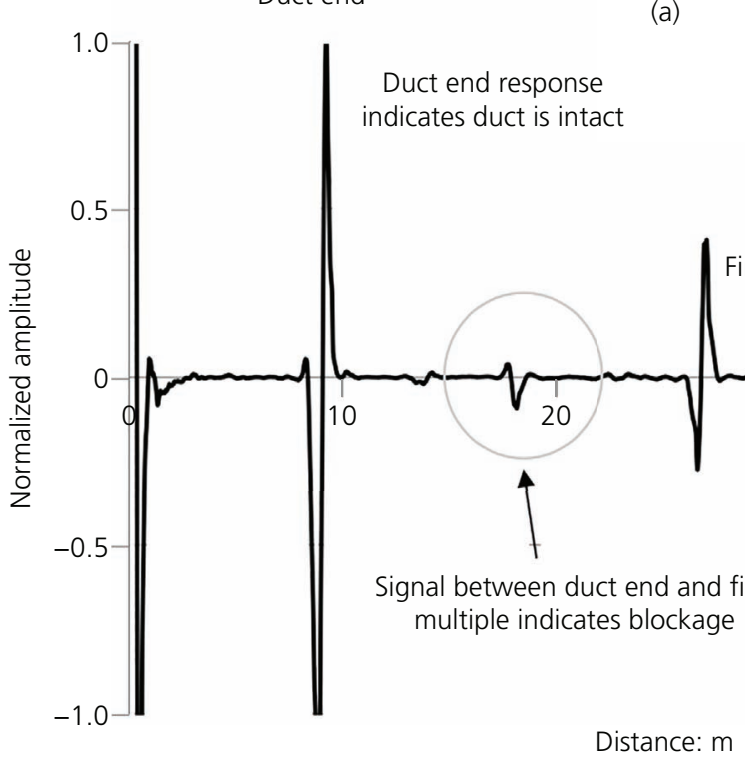

(b)

Figure 10. Transillumination signals for (a) duct $A$ and (b) duct $E$ 
duct terminus over a length of duct with that of the measured response provides a quality control to the in-duct features presented within the AR measurements. Using transillumination allows delineation of small features, such as duct joints, as seen for the metal duct (Figure 11 orange). However, it should be noted that transillumination measurements are not always feasible, particularly in a case where there are multiple full blockages along the duct length.
Further processing was performed on the AR test data. Time-domain signals corresponding to a plastic duct in good condition, a plastic duct blocked with a partial 30\% soil blockage and a duct blocked with driftwood (simulating tree root ingress) analysed in both measurement directions are shown in Figure 11. The reduction in amplitude for a duct end signal decreases faster for blocked ducts. If quantification of this event can be achieved, it would facilitate the assessment of duct condition.

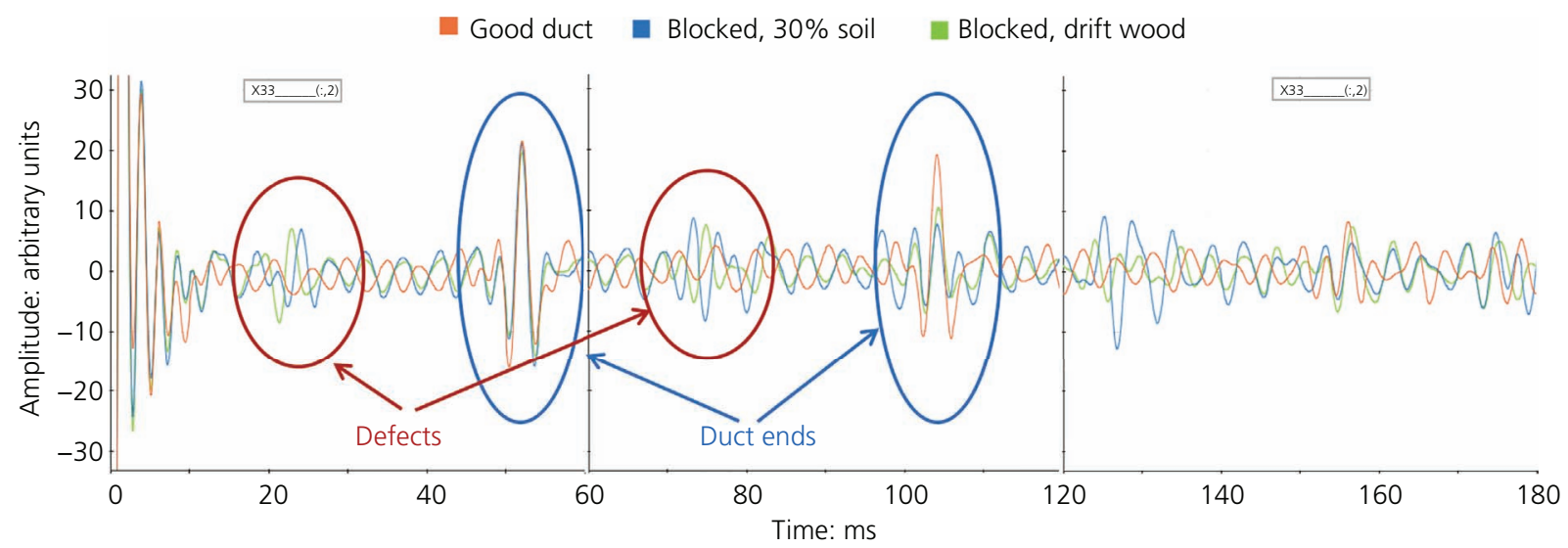

Figure 11. AR signals corresponding to a plastic duct in good condition, a plastic duct blocked with a partial $30 \%$ soil blockage and a duct blocked with driftwood
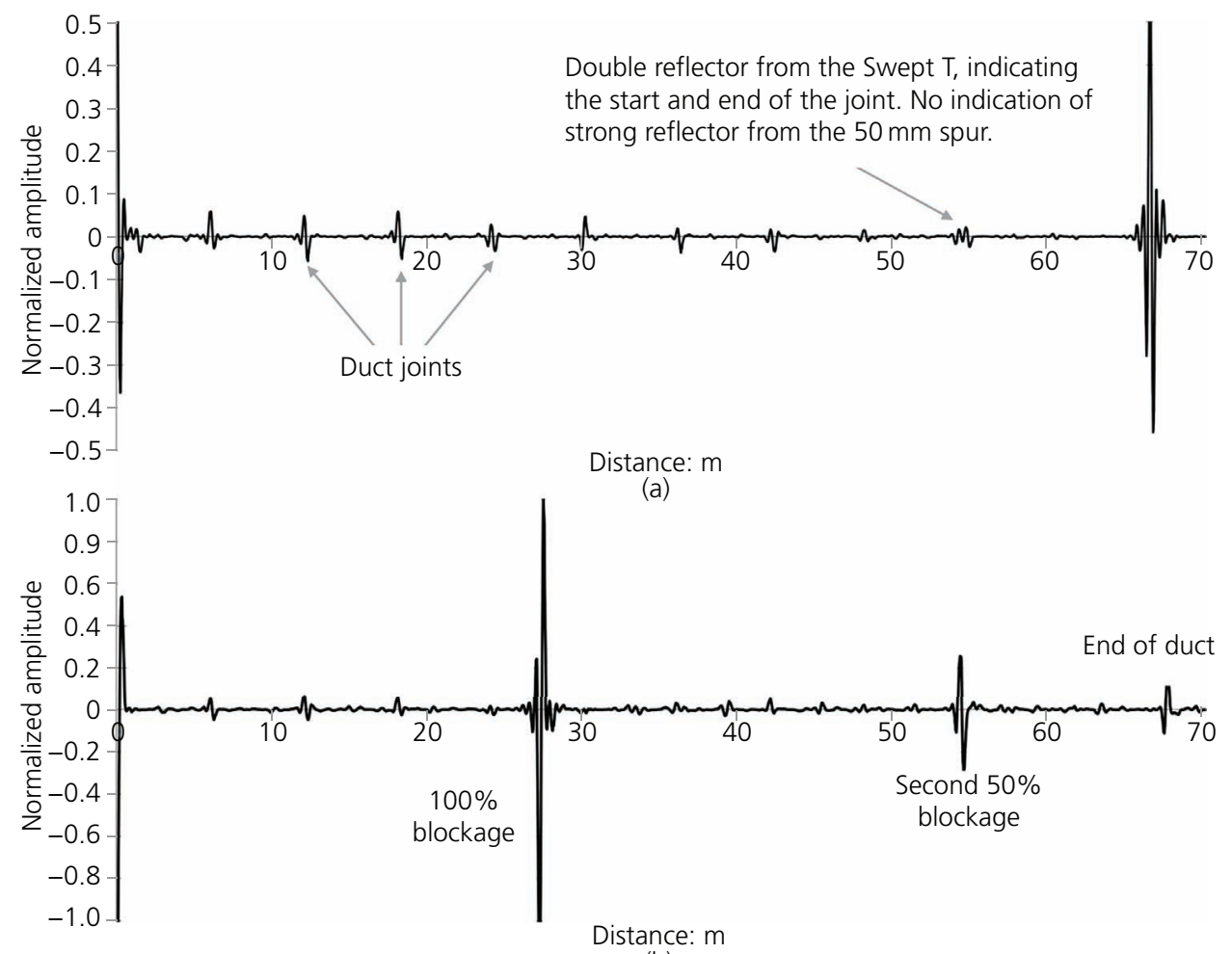

(b)

Figure 12. Recorded AR signal for the long duct above ground: (a) no blockages; (b) two blockages 
Frequency-domain (spectral) analyses of the individual signals were carried out for all defect scenarios, to assess the defect signature. The peaks identified in the frequency domain were averaged, depending on the central peak frequency, for all measurements corresponding to a single defect (i.e. six measurements, from both duct ends, three channels per measurement). It was found that blockages of less than $30 \%$ of the duct cross-sectional area were not distinguishable from the background noise. A total of 32 AR data sets were analysed. The analysis correctly identified all empty ducts as empty, and all single

Table 3. Summary of results

\begin{tabular}{|c|c|c|}
\hline Item & $\begin{array}{l}\text { In-duct acoustics } \\
\text { (reflectometry and } \\
\text { transillumination) }\end{array}$ & Surface GPR ${ }^{a}$ \\
\hline Location of duct & No & $\begin{array}{l}\text { Yes (from transverse } \\
\text { profiles) }\end{array}$ \\
\hline $\begin{array}{l}\text { Partial blockages } \\
\text { (single) }\end{array}$ & $\begin{array}{l}\text { Yes (reflectometry } \\
\text { single side and } \\
\text { transillumination) }\end{array}$ & $\begin{array}{l}\text { No, but larger partial } \\
\text { blockages over } 1 \mathrm{~m} \\
\text { length and } 60 \% \\
\text { annulus may be } \\
\text { detectable }\end{array}$ \\
\hline $\begin{array}{l}\text { Partial blockages } \\
\text { (double) }\end{array}$ & $\begin{array}{l}\text { Probably } \\
\text { (reflectometry } \\
\text { single side and } \\
\text { transillumination) }\end{array}$ & As above \\
\hline $\begin{array}{l}\text { Large full } \\
\text { blockage (single) }\end{array}$ & $\begin{array}{l}\text { Yes (reflectometry } \\
\text { only, single side) }\end{array}$ & Yes (from axial profiles) \\
\hline $\begin{array}{l}\text { Large full } \\
\text { blockage } \\
\text { (double) }\end{array}$ & $\begin{array}{r}\text { Yes (reflectometry } \\
\text { only, both sides) }\end{array}$ & Yes (from axial profiles) \\
\hline $\begin{array}{l}\text { Large full } \\
\text { blockage } \\
\text { (multiple) }\end{array}$ & $\begin{array}{l}\text { Does not identify the } \\
\text { middle blockage(s) }\end{array}$ & Yes (from axial profiles) \\
\hline Cable congestion & $\begin{array}{l}\text { No, but twisted } \\
\text { cables may be } \\
\text { detectable }\end{array}$ & No \\
\hline Flooded ducts & No & Yes \\
\hline $\begin{array}{l}\text { Leakage/saturated } \\
\text { ground }\end{array}$ & No & Yes \\
\hline
\end{tabular}

${ }^{a}$ Note that the tests in this case were conducted in only one soil type and it is commonly known that GPR results are affected by soil type.

A double blockage was two blockages separated by a certain distance. A multiple was more than two blockages in the same duct at the same time and double blockages (both partial and full, viz. 60 and 100\% of duct cross-section) were successfully detected. However, cable congestion was not identifiable. The one exception was the empty duct $\mathrm{E}$, where a blockage was identified (the central section comprised a narrower-diameter old pipe, which in effect is a restriction or blockage). This therefore shows its use if determining narrow sections along pipes or where there are repair collars (often used in telecom ducts). Based on these results, a second test was undertaken to determine the minimal resolvable distance between differently sized blockages. The tests indicated that a $30 \%$ blockage and a $50 \%$ blockage were individually resolvable if separated by greater than $10 \mathrm{~cm}$. However, if the larger blockage preceded the smaller blockage, a reflection from the leading edge of the smaller blockage was not recorded. That being said, a reflector from the end of the smaller duct was recorded. Increasing the frequency of the transmitted wave would permit the smaller separations to be resolved; however, the higher-frequency wavefront would be attenuated more rapidly, limiting the range.

To investigate if this system can operate over longer distances (99.5\% of BT ducts are below $250 \mathrm{~m}$ length), a $200 \mathrm{~m}$ duct was set up above ground, which included full and partial blockages, as well as collar repairs (reduced annulus by 10\%) and bends. Figure 12 shows the results over a $70 \mathrm{~m}$ stretch, where Figure 12(a) not only clearly shows the duct joints but also indicates that there is no blockage. In contrast, Figure 12(b) indicates two blockages and the relative amplitude indicates the size of the blockage. Both blockages were successfully detected.

\section{Discussion}

Table 3 summarises the results for the different defects for both GPR and in-duct acoustics. It clearly shows that GPR as a reconnaissance tool cannot only detect the location of the ducts but also provide some indication of full blockages and larger partial blockages, as well as indicate flooded ducts. While GPR has been used in the past to detect water leaks in buried pipes (Cheung and Lai, 2019; Lai et al., 2016), this is the first time it has been used to detect blockages in shallow ducts. This opens up new applications for GPR and could revolutionise the workflow used to install fibre optics in existing

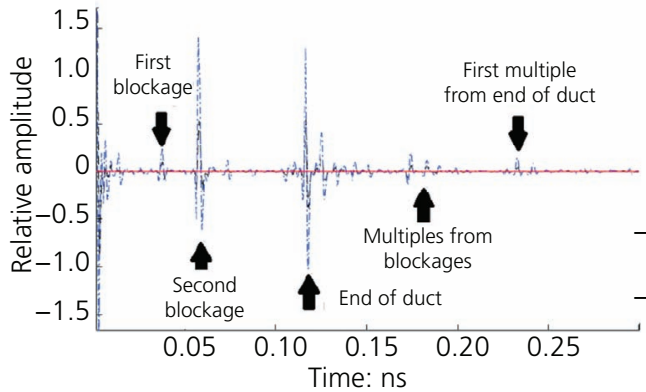

(a)

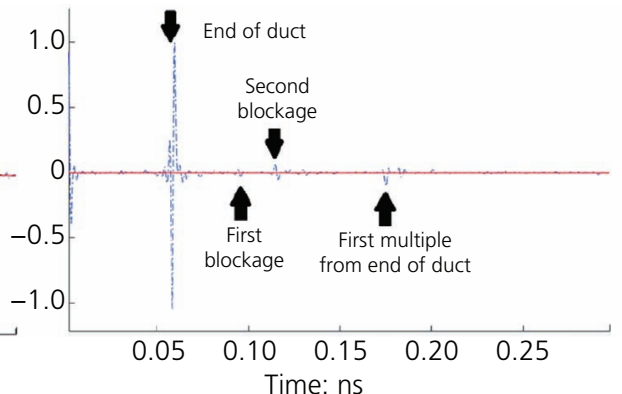

(b)

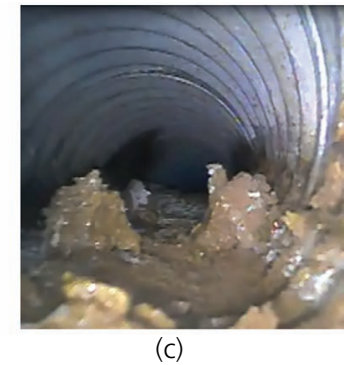

(c)

Figure 13. Recorded acoustic (a) reflected and (b) transmitted signals for a $150 \mathrm{~mm}$ dia. drainage duct recorded over $19.3 \mathrm{~m}$ along a railway track; (c) associated CCTV image of the partial blockage 
telecom ducts. It should be noted that the GPR survey needs to be conducted along the exact alignment of the duct for the data to be comparable. This in itself is achievable - albeit for shallow ducts - as GPR can be used to locate the duct by acquiring scans transverse to the duct at regular intervals along the duct. Moreover, post-processing is required currently to distinguish the small changes in the GPR response, although work is continuing to automate this, thereby allowing more on-site interpretation of the data. This is an important finding, as GPR does not require access to the duct from the manhole, thereby making it a fast technique to identify areas for further investigation. Optimising the processing is, however, vital, as traditionally GPR is post-processed in the office. To optimise the workflow and reduce costs, the GPR data have to be interpreted on-site to allow more immediate detailed investigation along the alignment of the duct if issues are found.

At the same time, it is clear that in-duct acoustics has the potential to detect partial blockages with the results immediately visible in the data, but the disadvantage is that it requires access to the duct by way of an inspection chamber. Once external environmental factors are eliminated or taken into consideration - for instance, the air temperature and atmospheric pressure within the duct - the number of potential reflector origins (i.e. defects, duct joints, Swept Ts, terminations and their respective multiples) is soon reduced to a constrained list that can be reasonably well defined in terms of response attributes (phase, amplitude, arrival time), which means that acoustic reflection and AT lend themselves to the application of real-time data analyses by machine learning. One such example is presented in Figure 3(a), which shows the characteristic double response with reverse polarity from a Swept $\mathrm{T}$ junction. As the physical size of this junction is an industry standard, the response is unlikely to change if the duct is clear from blockages and defects. While vibro-acoustic methods have demonstrated the ability to track utility pipelines over tens of metres (Muggleton et al., 2011; Muggleton and Brennan, 2012) and AR has been adopted for locating blockages within sewer pipes (Ali, 2010; Wang et al., 2009), it has not been used for the detection of blockages in small-diameter $(50$ and $100 \mathrm{~mm})$ ducts. Moreover, no commercial system is currently available for this application

The FINDIT project has taken an initial step down the path to being able to semi-automate the analysis of acoustic reflection and AT data with respect to the specific context of buried communication ducts, and many of the lessons learnt can be applied to various other buried assets such as water pipes. Therefore, the recommendation from this study is to use GPR in the first instance when planning the installation of FTTP but combine this with AR to detect partial blockages. These findings are significant, as they allow the assessment of the condition of the duct prior to installing the fibres. They supersede the current rodding process, as they can detect multiple defects and blockages in the ducts in one step. However, it should also be noted that there is currently no commercial AR device on the market. More development in the hardware is therefore needed.
The FINDIT project has shown that it is possible to detect blockages in telecom ducts using a combination of surface sensing with GPR and acoustic reflection and acoustic transmission from inside a manhole requiring access to the ducts. The findings clearly show that multiple defects can be identified, thereby surpassing the limitations of rodding, which can always identify only the first defect within a duct. This will enable a change in the workflow, where it is no longer the team installing the fibres identifying any blockages and then arranging the repair team, part of a different operational team, to be dispatched, often delaying the fibre installation by several days. This also suggests that if all blockages along the stretch of a duct are identified prior to the repair team getting on-site, these can all be fixed in one go. This not only leads to a reduction in return visits to site but also reduced disruption for road users, as sites do not have to be repeatedly blocked off and any repairs can be planned and executed in one go. Thus, while the findings do not reduce the direct costs of any repair, they significantly reduce the indirect costs due to return visits, interrupted work and excavations left open for longer than necessary.

Initial work using the in-duct acoustics on a 'real-world' site was carried out on a railway drainage duct that was a $150 \mathrm{~mm}$ dia. corrugated metal pipe with a length of $19.3 \mathrm{~m}$. Results correctly detected partial blockages of between 5 and $50 \%$ of the duct annulus at 5.5 and $10.4 \mathrm{~m}$. respectively, which was verified using CCTV, indicating that the blockages were very wet (Figure 13). This is an important finding, as all of the artificial blockages used at the BT test site were dry. However, further work is needed to take the sensing technology to more sites where additional challenges are likely, such as acoustic vibration from cars and more complex ducting networks.

\section{Conclusions}

In the UK, the majority of the communication network is buried in ducts, which are often several decades old. They have often collapsed or become blocked so that spare capacity cannot be used. There is currently no surface detection technology that can accurately locate the position of these defects (or even accurately locate the ducts in all circumstances), so time-consuming and costly manual rodding is performed, which cannot detect subsequent blockages, resulting in inadequate and inefficient repair planning, increasing the costs and causing disruption to road users.

The research described in this paper was conducted to investigate geophysical technologies that could potentially individually or in combination identify both the location of buried ducts and defects in these ducts, particularly blockages.

- After a careful review, a selection of possible geophysical techniques was tested on-site to assess their potential for application to locating buried ducts and identifying defects and blockages. These methods included EM methods, in-duct acoustics, GPR and seismics. As a result of a thorough evaluation on-site, it was determined that the most appropriate sensing technologies for buried telecommunications ducts were GPR and AR. 
- A controlled site was required to assess further GPR and AR/ AT for detecting duct damage and blockage, and hence, a bespoke test area was constructed, which proved an excellent evaluation environment for this application (and can be used for future technology evaluation)

Using a bespoke test site, the results showed the following:

- The GPR could detect the difference between a blocked and an unblocked duct and the difference between an intact and a damaged/corroded section of pipe.

- The GPR detected a difference between a partially blocked (up to $60 \%$ blockage) and an unblocked duct, but the difference in the amplitude of the signal was relatively small and close to the noise floor thus probably would not be discernible in practice.

- The results from the AT testing clearly showed that it could detect the difference between a blocked and a partially blocked duct, including the location of the end of the duct and the blockage.

- The AT testing also showed that with appropriate analysis of the results, this method could detect smaller defects, joints and Swept-Ts within the duct. However, due to access being required from both ends of the duct for this technique, if there are multiple full blockages in the duct, the system is not feasible and AR is better (where access from only one end of the duct is needed).

- Further processing of the AR test data showed that it had the ability to detect a range of blockages in buried ducts and blockages greater than $30 \%$ of the duct cross-section could be identified, particularly multiple blockages. It was possible to start characterising the reflection responses from different defects/blockages to aid assessment on-site.

- The AR technique was also tested on a $200 \mathrm{~m}$ long duct to test its effectiveness over more realistic distances needed in practice. It was found that it could resolve multiple blockages and also duct joints along the duct length.

With respect to the overall findings of the project

- GPR offers the ability to detect firstly the duct location and also to detect full blockages and larger percentages of partial blockages (including multiple blockages) without requiring access to the duct.

- In-duct acoustics (AR/AT) has the ability to detect partial blockages in ducts including multiple blockages but needs access to the duct through a manhole. However, these techniques can provide immediate information on duct condition.

Overall, the FINDIT project described in this paper has shown that using GPR and AR as part of a systematic workflow can provide information on the state (i.e. defects and blockages) of buried ducts prior to installing fibres on-site, thereby making the installation process more efficient.

\section{Acknowledgement}

The authors wish to acknowledge the support provided to this research project by Innovate UK Technology Strategy Board: Infrastructure Systems (82352-509379). All data used are proprietary and thus cannot be provided.

\section{REFERENCES}

Ali BTM (2010) Development of Acoustic Sensor and Signal Processing Technique. PhD thesis, University of Bradford, Bradford, UK.

Annan AP (2009) Electromagnetic principles of ground penetrating radar. In Ground Penetrating Radar: Theory and Applications (Jol HM (ed.)) Elsevier, Oxford, UK, pp. 3-40.

BGS (British Geological Survey) (2018) Borehole Records. BGS, Keyworth, UK. See https://metadata.bgs.ac.uk/geonetwork/srv/eng/ catalog.search\#/metadata/9df8df51-630c-37a8-e044-0003ba9b0d98 (accessed 22/05/2020).

Boddice D, Metje N and Tuckwell G (2017) Capability assessment and challenges for quantum technology gravity sensors for near surface terrestrial geophysical surveying. Journal of Applied Geophysics 146: 149-159, https://doi.org/10.1016/j.jappgeo.2017.09.018.

BSI (1990) BS 1377-2:1990: Methods of test for soils for civil engineering purposes. Classification tests. BSI, London, UK.

BSI (2014) PAS 128:2014: Specification for underground utility detection, verification and location. BSI, London, UK.

Burland J, Chapman T, Skinner H and Brown M (2012) ICE Manual of Geotechnical Engineering: Volume II. Institution of Civil Engineers, London, UK.

Butler DK (2005) Near-surface Geophysics. Society of Exploration Geophysicists, Tulsa, OK, USA.

Cassidy NJ (2009) Electrical and magnetic properties of rocks, soils and fluids. In Ground Penetrating Radar: Theory and Applications (Jol HM (ed.)). Elsevier, Oxford, UK, pp. 41-72.

Cheung BWY and Lai WWL (2019) Field validation of water-pipe leakage detection through spatial and time-lapse analysis of GPR wave velocity. Near Surface Geophysics 17(3): 231-246, https://doi.org/10. 1002/nsg.12041.

Curioni G, Chapman DN and Metje N (2017) Seasonal variation of electromagnetic properties measured by TDR on a sandy soil and its impact on GPR. Journal of Applied Geophysics 14(1): 34-46, https:// doi.org/10.1016/j.jappgeo.2017.01.029.

Das Y, McFee JE, Toews J and Stuart GC (1990) Analysis of an electromagnetic induction detector for real-time location of buried objects. IEEE Transactions on Geoscience and Remote Sensing 28(3): 278-288, https://doi.org/10.1109/36.54354.

Datta S and Sarkar S (2016) A review of different pipeline fault detection methods. Journal of Loss Prevention in the Process Industries 41: 97-106.

Demirci S, Yigit E, Eskidemir IH and Ozdemir C (2012) Ground penetrating radar imaging of water leaks from buried pipes based on backprojection method. NDT\&E International 47: 35-42, https://doi.org/ 10.1016/j.ndteint.2011.12.008.

Duan HF, Lee PJ, Ghidaoui MS and Tuck J (2014) Transient waveblockage interaction and extended blockage detection in elastic water pipelines. Journal of Fluids and Structures 46: 2-16, http://doi.org/10. 1016/j.jfluidstructs.2013.12.002.

Duan W, Kirby R, Prisutova J and Horoshenkov KV (2015) On the use of power reflection ratio and phase change to determine the geometry of a blockage in a pipe. Applied Acoustics 87: 190-197, http://doi.org/10. 1016/j.apacoust.2014.07.002.

Farrimond M (2008) The importance of seeing through the ground - a utility perspective. In Proceedings of the 12th International Conference on Ground Penetrating Radar (Rogers CDF and Chingnell Rj (eds)). University of Birmingham, Birmingham, UK. 
Hunaidi O and Giamou P (1998) Ground-penetrating radar for detection of leaks in buried plastic water distribution pipes. In Proceedings of the Seventh International Conference on Ground-Penetrating Radar (GPR'98). Radar Systems and Remote Sensing Laboratory, University of Kansas, Lawrence, KS, USA, pp. 783-786.

Jol HM (1995) Ground penetrating radar antennae frequencies and transmitter powers compared for penetration depth, resolution and reflection continuity. In Geophysical Prospecting 43(5): 693-709, https://doi.org/10.1111/j.1365-2478.1995.tb00275.x.

Jol HM (ed.) (2009) Ground Penetrating Radar: Theory and Applications Elsevier, Oxford, UK.

Kim S (2014) Inverse transient analysis for a branched pipeline system with leakage and blockage using impedance method. Procedia Engineering 89: 1350-1357, https://doi.org/10.1016/j.proeng.2014.11. 456.

Kim DS, Shin S, Choi GB et al. (2017) Diagnosis of partial blockage in water pipeline using support vector machine with fault-characteristic peaks in frequency domain. Canadian Journal of Civil Engineering 44(9): 707-714, https://doi.org/10.1139/cjce-2016-0615.

Koppenjan S (2008) Ground penetrating radar systems and designs. In Ground Penetrating Radar: Theory and Applications (Jol HM (ed.)). Elsevier, Oxford, pp. 73-99.

Lai WWL, Chang RKW, Sham JFC and Pang K (2016) Perturbation mapping of water leak in buried water pipes via laboratory validation experiments with high-frequency ground penetrating radar (GPR). Tunnelling and Underground Space Technology 52: 157-167, https://doi.org/10.1016/j. tust.2015.10.017.

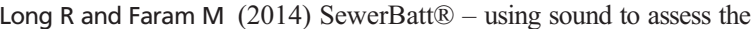
condition of sewers and drains. Proceedings of the 8th European Waste Water Management Conference, Warwick, UK.

McDowell PW, Barker RD, Butcher AP et al. (2002) Geophysics in Engineering Investigations. Construction Industry Research and Information Association, London, UK, Geological Society Engineering Geology Special Publication 19.

Milsom J and Eriksen A (2011) Field Geophysics, 4th edn. WileyBlackwell Oxford, UK.

MTU (Mapping the Underworld) (2021). See https://www. mappingtheunderworld.ac.uk (accessed 25/08/2021).

Muggleton MJ and Brennan JM (2012) The use of acoustics in the water industry. Water \& Sewerage Journal 4: 35-36.

Muggleton JM, Brennan MJ and Gao Y (2011) Determining the location of buried plastic water pipes from measurements of ground surface vibration. Journal of Applied Geophysics 75(1): 54-61, https://doi.org/ 10.1016/j.jappgeo.2011.06.030.

NJUG (National Joint Utilities Group) (2018) Streetworks UK Guidelines on the Positioning and Colour Coding of Underground Utilities Apparatus. NJUG, London, UK, vol. 1, issue 9. See http://streetworks. org.uk/wp-content/uploads/2018/11/VOL-1-reviewed.pdf (accessed 08/02/2021).

Ofcom (Office of Communications) (2017) WLA Market Review: Consultation on Pricing Proposals for Ducts and Pole Access Remedies. Ofcom, London, UK. See https://www.ofcom.org.uk/_data/assets/pdf_file/0019/ 105427/consultation-dpa-pricing.pdf (accessed 17/07/2020)

Openreach (2019) Duct Laying (Quick Guide). Openreach Limited, London, UK, Document PHME 84986. See https://www.openreach. com/fibre-broadband/fibre-for-developers/guides-and-handbooks (accessed 17/07/2020).

Openreach (2020) Physical Infrastructure Pricing Schedule. Openreach Limited, London, UK. See https://www.openreach.co.uk/orpg/home/ products/pricing/loadProductPriceDetails.do?data $=\%$ 2BxxzCdLXIVS2hHTfdTw\%2FyFpqGjRTzjXv9ULYqsx2PF89q\% 2FCUHfmZJHKkF036xG69e6YShZ82RgLOGLsH2e9\%2Bmw\%3D\% 3D (accessed 25/08/2021).

Papadopoulou KA, Shamout MN, Lennox B et al. (2008) An evaluation of acoustic reflectometry for leakage and blockage detection. Proceedings of the Institution of Mechanical Engineers, Part C: Journal of Mechanical Engineering Science 222(6): 959-966, https://doi.org/10. 1243/09544062JMES873.

Perez-Gracia V, Di Capua D, Gonzales-Drigo R and Pujades L (2009) Laboratory characterization of a GPR antenna for high-resolution testing. Radiation pattern and vertical resolution. $N D T \& E$ International 42(4): 336-344.

Pettinelli E, Di Matteo A, Mattei E et al. (2009) GPR response from buried pipes: measurement on field site and tomographic reconstructions. IEEE Transactions on Geoscience and Remote Sensing 47(8): 2639-2645, https://doi.org/10.1109/TGRS.2009.2018301.

Plati C and Derobert X (2015) Inspection procedures for effective GPR sensing and mapping of underground utilities and voids, with a focus to urban areas. In Civil Engineering Applications of Ground Penetrating Radar (Benedetto A and Pajewski L (eds)). Springer, Heidelberg, Germany, pp. 97-123.

Reynolds JM (2011) An Introduction to Applied and Environmental Geophysics. Wiley-Blackwell, Oxford, UK.

Rial FI, Pereira M, Lorenzo H, Arias P and Novo A (2009) Resolution of GPR bowtie antennas: an experimental approach. Journal of Applied Geophysics 67(4): 367-373, https://doi.org/10.1016/j.jappgeo.2008.05. 003.

Robins L (2005) On-line diagnostics techniques in the oil, gas, and chemical Industry. Proceedings of the 3rd Middle East Nondestructive Testing Conference \& Exhibition, Manama, Bahrain.

Thomas AM, Metje N, Rogers CDF and Chapman DN (2006) Ground penetrating radar interpretation as a function of soil response complexity in utility mapping. Proceedings of the 11th International Conference on Ground Penetrating Radar, Columbus, OH, USA, p. 9.

Torres MN, Rodriguez JP and Leitao JP (2017) Geostatistical analysis to identify characteristics involved in sewer pipes and urban tree interactions. Urban Forestry \& Urban Greening 25: 36-42, https://doi. org/10.1016/j.ufug.2017.04.013.

Utsi EC (2017) Ground Penetrating Radar: Theory and Practice. Butterworth-Heinemann, Oxford UK

Wang X, Lennox B, Turner J, Lewis K and Ding Z (2009) Blockage detection in long lengths of pipeline using a new acoustic method. Proceedings of the 16th International Congress on Sound and Vibration, Cracow, Poland. Curran Associates, New York NY, pp. 1-8.

Weiler KW, Steenhuis TS, Boll J and Kung KJS (1998) Comparison of ground penetrating radar and time-domain reflectometry as soil water sensors. Soil Science Society of America Journal 62(5): 1237-1239, https://doi.org/10.2136/sssaj1998.03615995006200050013x.

\section{How can you contribute?}

To discuss this paper, please email up to 500 words to the editor at journals@ice.org.uk. Your contribution will be forwarded to the author(s) for a reply and, if considered appropriate by the editorial board, it will be published as discussion in a future issue of the journal.

Proceedings journals rely entirely on contributions from the civil engineering profession (and allied disciplines). Information about how to submit your paper online is available at www.icevirtuallibrary.com/page/authors, where you will also find detailed author guidelines. 